\title{
"La solución japonesa": Imágenes de Japón como modelo de paz social frente a la conflictividad laboral española
}

\author{
Julio César Iglesias Rodríguez ${ }^{1}$
}

Recibido 15/01/2020; Aceptado 25/06/2020

Resumen. En este artículo se estudian las representaciones de Japón en la Asturias de los años ochenta y noventa, con especial atención a la transformación de las relaciones de producción como consecuencia de la aplicación de técnicas sociolaborales de inspiración japonesa. Al respecto, se repasa la imagen general de Japón en España a través de varios medios de comunicación, y se examinan con mayor detalle algunos conflictos laborales, especialmente el de la planta de Suzuki en Gijón. Este trabajo permite sugerir que el discurso orientalista presentó el "milagro económico" japonés como un producto de su inclinación cultural al consenso, contribuyendo así a naturalizar determinados discursos que exigían a los sindicatos que sustituyeran la lucha de clases por la cooperación entre productores.

Palabras clave: Orientalismo, modelo japonés, neoliberalismo, movimiento obrero, Asturias

\section{[en] "The Japanese solution": Imagery of Japan as a social peace model versus the Spanish labour unrest}

Abstract. This paper studies the imagery of Japan in the Asturias of the eighties and nineties with a special focus on the evolution of the relations of production resulting of the application of social and labour techniques of Japanese inspiration. In this regard, the country image of Japan in Spain is examined across different national and local media, and specific labour conflicts are looked into in greater detail, especially that of the Suzuki factory in Gijón. This paper suggests that the Orientalist discourse presents the Japanese "economic miracle" as a product of its cultural inclination towards consensus, thus contributing to naturalize approaches that called for unions to replace class struggle by cooperation among producers. Keywords: Orientalism, Japanese model, neoliberalism, labour movement, Asturias

Sumario: 1. Introducción. 2. Aspectos de la representación occidental de Japón. 3. "La esperanza amarilla": imágenes españolas del modelo japonés. 4. La imagen de Japón en la Asturias de la reconversión industrial. 5. "Del peligro amarillo a la salvación oriental". El conflicto de Suzuki en Gijón. 6. Conclusiones. Obras citadas.

Cómo citar: Iglesias Rodríguez, J. C. "La solución japonesa": Imágenes de Japón como modelo de paz social frente a la conflictividad laboral española. Sociología del Trabajo, nº6 (2020), 35-46.

\section{Introducción}

En este artículo se estudian las imágenes de Japón en la Asturias de los años ochenta y noventa a través de la prensa, con particular énfasis en las representaciones de Japón como modelo económico y difusor de nuevas metodologías laborales; al respecto, se revisará con cierto detalle la información generada en torno al conflicto laboral de 1990 en la fábrica gijonesa de Suzuki. Se pretende discernir algún aspecto significativo de los vínculos entre el discurso orientalista y la entusiasta recepción de lo que se denominó "modelo japonés", especialmente en lo que hace a su relación con determinadas posiciones políticas que aspiraban a diseñar un entorno fabril libre de conflictos de clase. El artículo se estructura en cuatro bloques: en el primero se inscribe el modelo japonés en la trayectoria histórica del discurso orientalista y se plantean algunas de las premisas teóricas de este trabajo; el segundo apartado revisa la

\footnotetext{
Universidad de Oviedo.

UO5772@uniovi.es
} 
imagen del modelo japonés en la prensa española y estudia algún aspecto de su implantación en el mundo laboral, especialmente a través del caso de la fábrica de Suzuki en Linares; el tercer bloque del artículo aborda una panorámica general de las imágenes de Japón en la Asturias de la reconversión industrial, y el cuarto se detiene en la cobertura mediática del ya mencionado conflicto de Suzuki en Gijón. En cuanto al uso de las fuentes, debe destacarse que este artículo forma parte de una investigación más amplia sobre los usos sociales y políticos de las imágenes de Japón en Occidente, uno de cuyos ejes documentales más relevantes fueron los medios de comunicación españoles, examinados desde finales del siglo XIX hasta principios del XXI con especial atención a los periódicos ABC, La Vanguardia, El País y al asturiano La Nueva España. Con esta selección de fuentes se pretendía reconstruir parcelas significativas de la difusión de las imágenes de Japón en el espacio público español a través de medios de comunicación de alto impacto en número de lectores, variedad ideológica y probada capacidad de incidencia en los debates públicos. $L a$ Vanguardia, en particular, facilitaba estudiar con mayor detalle la particular relación de Cataluña con la cultura japonesa. En el caso asturiano, La Nueva España, de tendencia liberal, es el periódico de mayor tirada de la comunidad, hegemónico en Oviedo. Para estudiar la cobertura del conflicto de Suzuki se consultaron también los otros grandes diarios asturianos en papel: El Comercio, afincado en Gijón, y La Voz de Asturias, medio de referencia para muchos lectores progresistas. Respecto a la difusión de los tres periódicos, en 2018 La Nueva España registró una tirada de 34.877 ejemplares frente a los 13.647 de El Comercio. La distancia entre ambos diarios, sin embargo, era inferior en el año 2000 (57.560 frente a 25.703), y más aún en 1990, el año en que tuvo lugar la huelga en Suzuki, cuando $L a$ Nueva España tuvo una tirada de 38.510 ejemplares, por los 25.830 de El Comercio. En cuanto a La Voz de Asturias, su desaparición en 2012 no debe hacer perder de vista su amplia difusión en el período estudiado, en tanto que en 1990 tenía una tirada de 22.172 ejemplares, a escasa distancia de la de El Comercio. ${ }^{2}$

\section{Aspectos de la representación occidental de Japón: armonía y productividad}

La historia de las imágenes de Japón en Occidente ha oscilado entre las representaciones de un paraíso exótico bello e inmaculado, una Arcadia en la que encontrar la paz espiritual, y la concepción de Japón como el enemigo definitivo de Occidente, capaz de liderar a las masas asiáticas en una cruzada para destruir la democracia liberal. Estas representaciones se nutren de estereotipos cuyo origen podría remontarse a los primeros contactos de los misioneros cristianos con Japón, aunque cabe apuntar con Gustafsson que resulta -al menos para los objetivos de este artículomenos fructífero intentar desentrañar la realidad enmascarada por los estereotipos que indagar en la forma en que estos “crean y recrean" su propia realidad (Gustafsson, 2004: 144). ${ }^{3}$ Así, el movimiento pendular entre la imaginación utópica y distópica de Japón no opone concepciones forzosamente contrapuestas, en tanto que la representación del paraíso exótico y la del "peligro amarillo" se sustentan en el mismo repertorio de imágenes orientalistas. ${ }^{4}$ Entre elogiar que el interés del colectivo prevalezca frente al egoísmo particular y vituperar a las "hordas orientales" que siguen ciegamente a sus líderes solo hay, a menudo, una diferencia de matiz e intencionalidad social o política. ${ }^{5}$ Esta dualidad de las representaciones de Japón en Occidente, configurada a lo largo de un complejo proceso histórico, se consagra en buena medida al final de la segunda guerra mundial, cuando los estrategas de las fuerzas estadounidenses de ocupación comienzan a buscar conceptos que les permitan rehabilitar la imagen del ya derrotado enemigo japonés e intervenir en su sociedad para convertirlo en un aliado fiable en el Pacífico. ${ }^{6}$ La infantilización del pueblo japonés fue una de las claves de este período; para MacArthur, los japoneses apenas eran "niños de 12 años" si se los comparaba con las naciones occidentales (Shibusawa, 2006: 55), mientras que el psicólogo Geoffrey Gorer afirmaba que los japoneses eran tan crueles con los países débiles como lo eran los niños con sus madres (Gorer, 1941: 15-16). Así, se contribuía a establecer una narrativa que limitaba las responsabilidades bélicas a unos pocos líderes militaristas y favorecía que Estados Unidos se arrogase la misión histórica de alejar al Japón de las armas y conducirlo hacia la democracia. La antropóloga Ruth Benedict, contratada por el gobierno estadounidense para investigar la sociedad japonesa, popularizó la metáfora del conflicto entre las dos almas del Japón, la tradicional y la militarista, en El crisantemo y la espada (1946), probablemente la obra que más ha condicionado las representaciones contemporáneas de Japón. ${ }^{7}$ Benedict describió la sociedad japonesa como un sistema jerárquico extremadamente rígido, orientado por

Todos los datos proceden de los informes de la OJD (Oficina de Justificación de la Difusión).

Para un estudio sobre los estereotipos como dispositivos de control social véase Harrison White (1992).

En este artículo "orientalismo" se referirá al concepto con el que Edward Said amalgamó un conjunto de discursos gestados en el seno de las estructuras de poder y conocimiento del colonialismo, que trasladaban una visión simplificada del mundo árabe, permitían a Occidente definirse, por contraste, como fuente exclusiva de la modernidad, y legitimaban las conquistas imperialistas. (Said, 2002) Varios autores han polemizado con diversos aspectos teóricos y metodológicos de la obra de Said (Ahmad, 1994; Bhabha, 2002; Dreyfus, 2005); por otra parte, desde el ámbito de los estudios sobre Japón algunos especialistas han resaltado que la peculiar relación histórica de Japón con Occidente plantea problemas específicos que exigen matizar o expandir la teoría del orientalismo. (Minear, 1980; Karatani, 2002)

Se podría recordar, por poner un solo ejemplo entre muchos posibles, que la fantasía de una sociedad benévola y tiránicamente encuadrada por una casta de funcionarios-samurái descrita por H.G. Wells en Una utopía moderna (1905) comparte la fascinación por los valores marciales y espirituales de los guerreros japoneses plasmada por E.H. Fitzpatrick en The Coming Conflict of Nations (1909), novela encuadrada en la literatura del "peligro amarillo".

6 Lo que incluía no solo dotar al país de estructuras democráticas sino desactivar el peligro de que Japón se inclinase hacia el bando comunista. (Takemae, 2002; Oinas-Kukkonen, 2003)

Merece la pena apuntar que la interpretación culturalista no era el único camino a disposición de las autoridades estadounidenses. Helen Mears (1948) explicó, en un trabajo lamentablemente olvidado, el conflicto entre Japón y Estados Unidos como la consecuencia más o menos inevitable del choque en el Pacífico de dos proyectos expansionistas. No sorprende que las autoridades de la ocupación se inclinasen por las teorías de Benedict o Gorer. 
una estructura de normas y obligaciones ritualizadas en la que cada individuo conoce -y está culturalmente determinado para aceptar- su rol, atribuciones y deberes (Benedict, 1946: 47). Sus planteamientos, discutidos desde gran parte de la comunidad científica, ${ }^{8}$ fueron aún así particularmente influyentes en el propio Japón, y contribuyeron a la difusión de un cuerpo de discursos conocido como nihonjinron, literalmente "discursos sobre los japoneses", que describían en términos nacionalistas la cultura y etnia japonesas. Autores como Chie Nakane o Takeo Doi reutilizaron y adaptaron tradiciones nativistas para explicar Japón como una sociedad vertical, colectiva y respetuosa de las jerarquías. A pesar de la prolífica literatura científica que refuta las premisas y la base documental esgrimida por este tipo de discursos, gestados en su gran mayoría al margen de la comunidad académica, no cabe dudar de su decisiva influencia en la representación occidental de Japón. ${ }^{9}$

Tras la posguerra, la admiración por la vertiginosa reconstrucción de las estructuras sociales y productivas japonesas se transformó, a medida que la nación asiática se convertía en una potencia económica, en afán por aprehender y, eventualmente, imitar sus logros. Destaca al respecto The Japanese Factory (1958) de James Abegglen, una de las obras más citadas del ámbito de la sociología laboral durante los sesenta (Mortimer Mash y Mannari, 2015: 7); directamente inspirado por Benedict, Abegglen sugería que la tradición de lealtades mutuas del comunitarismo medieval japonés moldeaba sus relaciones sociales contemporáneas. ${ }^{10}$ Esta obra anticipa un prolijo género literario de diversa naturaleza que relacionaba estrechamente los rasgos culturales japoneses con el éxito de su economía, tanto para hacerla inteligible $-\mathrm{y}$, eventualmente, replicable-, como para alertar de la amenaza que su poder suponía para Occidente. ${ }^{11}$ Uno de los trabajos fundamentales en la difusión de este interés por el modelo japonés y sus metodologías productivas fue La máquina que cambió el mundo (Womack et al., 1992), que asentó, como es sabido, el uso del término "producción ligera" para referirse a las prácticas laborales atribuidas al toyotismo. ${ }^{12}$ Bonazzi destaca cuatro principios esenciales de la "producción ligera": eliminar recursos y procesos redundantes, implicar al conjunto de la comunidad empresarial en las decisiones relativas a la producción, fomentar la participación de los subcontratistas y, por último, crear un producto con "cero defectos", sin aumento de los costes (Bonazzi, 1993: 3-6). Holm-Detlev Köhler, por su parte, recuerda que la "producción ligera" se convirtió en el paradigma de toda una generación de empresarios y ejecutivos de todo el mundo, y resume los dos mensajes esenciales de Womack, Jones y Roos: por un lado, las empresas debían adaptarse a la pujanza de los empresarios japoneses, supuestamente capaces de producir lo mismo en la mitad de tiempo, de tal manera que se trataba de "cambiar o morir"; por otro lado, La máquina que cambió el mundo reiteraba uno de los rasgos fundamentales de la representación de Japón en el mundo occidental de los años ochenta: Occidente podía encapsular los misterios del éxito japonés y aplicarlos en su propio beneficio (Köhler, 2001: 76).

\section{3. "La esperanza amarilla": imágenes españolas del modelo japonés}

La imagen de Japón en España desde finales del siglo XIX no es ajena a la admiración por su desarrollo económico, la calidad de su sistema educativo, las virtudes marciales de su ejército y la cohesión de su sociedad. ${ }^{13}$ Esta percepción genéricamente favorable se mantuvo, siempre observando todo tipo de matices ante un juicio tan amplio, durante la dictadura franquista, período en el que se adivina también cierta afinidad por una nación a la que algunos sectores percibían como una víctima de las potencias liberales, comprometida, al igual que España, en la lucha contra el comunismo, que pugnaba por mantener su identidad frente a las tendencias disolventes de la modernidad. ${ }^{14}$ No faltaban, evidentemente, textos críticos u hostiles hacia Japón, pero España, a diferencia de lo que sucedía en gran parte de Occidente, anhelaba las inversiones japoneses más de lo que podía temer la competencia de sus productos. De hecho, ya desde los años setenta abundan críticas a Gran Bretaña o Estados Unidos, cuyos ataques y advertencias contra Ja-

Kazuko Tsurumi ya lamentaba, en los años cuarenta, que Benedict seleccionara sistemáticamente textos de las autoridades imperiales como indicadores globales del comportamiento individual y colectivo japonés (Tsurumi, 2015: 224). Para Jennifer Robertson, el éxito de Benedict tiene mucho que ver con que hiciera que los "antes inescrutables" japoneses se volvieran "transparentes como el cristal". (Robertson, 1998: 302)

Salvando los matices, la comunidad científica coincide en identificar en la nihonjinron una suerte de "nacionalismo cultural conservador" (Sugimoto y Mouer, 1986: 406), que "esencializa la cultura japonesa en la construcción y representación de la propia identidad” (Guarné, 2011: 741) de manera que permite una "percepción intuitiva de la cultura japonesa que solo los nativos pueden alcanzar" (Befu, 2001: 67). Argumentos que matizan o discuten estas críticas en Sugiyama Lebra (2005) y Bouchard (2017: 37-63).

10 Para una crítica temprana de Abegglen véase Taira (1970), que reprocha que el autor ignore que los patrones de desarrollo histórico y económico japoneses no eran en absoluto excepcionales. Interesa también la introducción a la recepción en Japón de las teorías organizacionales estadounidenses que ofrecen Beechler, Ito y Pucik (1986).

11 Algunos trabajos académicos en Ronald Dore (1987, 2002), Hofstede y Bond (1988) o Trompenaar y Hampden-Turner (1993). En el campo de la divulgación la obra más célebre en lengua inglesa es la de Vogel (1979), aunque autores como Thurow (1992) o Fallows (1991), entre muchos otros, gozaron también de amplia difusión.

12 Debe tenerse en cuenta que las prácticas de producción japonesa distan de responder a un patrón uniforme, y que buena parte de los argumentos que afirmaban la superioridad general técnica y metodológica japonesas extrapolaban, en buena medida, el caso de Toyota al resto de empresas. (Köhler, 2001: 84-86)

13 Algún ejemplo en «La enseñanza en el Japón», La Escuela y el Hogar, 9 de octubre de 1893; Rafael Comenge, «El Marqués de Ito», El Imparcial, 27 de septiembre de 1905; «Un libro de grandeza», El Imparcial, 4 de julio de 1908. No debe perderse de vista, de todas formas, que el interés por Japón fue comparativamente inferior al que se vivió en otros países europeos. Para una visión general interesa consultar, entre otros, Barlés (2003) y Almazán y Rodao (2006).

14 Es conocida la pasión por Japón, en particular por su cultura guerrera, de figuras tan relevantes del fascismo español como Giménez Caballero. Este último fue corresponsable de la traducción de 1941 de Bushidō, de Nitobe Inazō; para contextualizarla consúltese Beeby y Rodríguez (2009). 
pón se consideraban puros ejercicios de hipocresía o se despachaban como un problema ajeno al mercado español. ${ }^{15}$ La admiración por las tradiciones japonesas denotaba, a menudo, una visión conservadora de su sociedad, concebida como una suerte de guía para recuperar valores sepultados por la modernidad. Fraga Iribarne, por ejemplo, confesaba inclinarse por la idea de que los factores de uniformidad debían prevalecer sobre los de la diversidad, y afirmaba que Japón estaba "lleno de buenos ejemplos" de respeto a las jerarquías y a los valores tradicionales. El japonés, para Fraga, valora, por encima de todo, "el orden, la limpieza, la estética, el estilo, el código del honor, el poder presentar una hoja limpia y un prestigio. Sin ellos, la vida carece de sentido." ${ }^{16}$ En una línea muy similar abundaban artículos que veían en el feudalismo la clave de bóveda del milagro japonés, ya que los trabajadores pertenecían en "cuerpo y alma" a su empresa y los sindicatos colaboraban con los productores en lugar de "promover conflictos". ${ }^{17}$ Se podrían multiplicar ejemplos que reiteran una concepción no conflictual de la cultura japonesa, y no se alejarían mucho del espíritu con el que Rosa Ovejero diagnostica en 1985 que el "milagro japonés” tenía que ver con "la productividad y la paz social", actitudes de cooperación que devenían de "la colaboración armoniosa entre empresarios y asalariados", inscrita en la cultura oriental. ${ }^{1819}$ Japón sería, expresado sin tapujos por multitud de articulistas, un antídoto contra la lucha de clases y el "antagonismo social que nos conduce a un callejón de salida que, al decir de algunos, solo puede terminar con la derrota de una de las partes en lucha." ${ }^{20}$ Ibáñez Escofet, en memorable expresión, afirmó que muchas naciones emancipadas tras la Segunda Guerra Mundial "pusieron a Marx como guía cuando hubiera sido mejor un empresario japonés." ${ }^{21}$ La idea del líder japonés como guía se consolidó durante la campaña peruana de 1990, cuando Fujimori se presentó a sí mismo como encarnación étnica del modelo japonés. ${ }^{22}$ Carlos Sentís afirmaba, en fin, que japonizar Perú implicaría mejoras económicas, sociales y tecnológicas, articuladas desde el servicio gregario a la nación; “un japonés, incluso el emperador, es muy poca cosa. Son 'los' japoneses quienes, manos a la obra, pasaron de la indigencia a la abundancia." 23

Es necesario, en todo caso, mencionar también las reservas que el modelo laboral despertaba en parte de la sociedad. Durante los años ochenta los medios occidentales intensificaron las críticas al infernal ritmo de vida de los trabajadores japoneses, mostrando especial fascinación por el fenómeno de la muerte por saturación de trabajo, el karōshi. ${ }^{24}$ No obstante, abundaban los textos que situaban la supuesta adicción por el trabajo nipona en el extremo opuesto a la "vagancia" de los sindicatos occidentales. ${ }^{25}$ Esta imagen contribuye a contextualizar que el término "japonización" termine por ser percibido entre los sindicatos como un ataque a los derechos de los trabajadores, una nueva "forma de vinculación del trabajador a la empresa, que rememorarían a los antiguos siervos de la gleba, trasladados a la era posindustrial." ${ }^{26}$ Esta apreciación podría resumirla la visión de un sindicalista de una fábrica de Seat en la que ya se aplicaba el sistema toyotista, del que afirmaba que era "impecable desde el punto de vista tecnológico" pero que su objetivo último era "cargarse el sindicalismo de clase" para sustituirlo por el "amor a la empresa". ${ }^{27}$ La conflictiva implantación de estas nuevas metodologías se puede observar con detalle en el caso de la fábrica de Santana Motor, en Linares (Jaén), participada por Suzuki desde 1985 y adquirida definitivamente en 1993. Rafael Cuesta Ávila da cuenta de las resistencias de los trabajadores santaneros ante prácticas como la videograbación o los círculos de calidad y, en términos generales, pormenoriza su resistencia frente a la reconfiguración de las relaciones de poder en la fábrica; al respecto, el autor afirma que la transferencia de técnicas sociolaborales foráneas debe analizar previamente la cultura corporativa de acogida, si no quiere verse "abocada al rechazo de los trabajadores" (Cuesta Ávila, 2003: 308-309). También la prensa se hizo eco del profundo malestar en la plantilla de Santana Motor ante estas y otras prácticas laborales; asimismo, los medios recogieron episodios xenófobos ocurridos en la época de las grandes movilizaciones populares de 1993 y 1994 contra el cierre de la fábrica, que provocaron que los dueños

\footnotetext{
15 Algunos ejemplos en Ángel Zuñiga, «La gira de los adioses (3) La fuerza del yen», La Vanguardia, 23 de abril de 1978; Ramón Vilaró, «La calidad es el factor prioritario para los productos “made in Japan”», El País, 8 de enero de 1979; Carlos Sentís, «A la hora del Japón», La Vanguardia, 10 de febrero de 1980; Juan Fernando Dorrego, «Las fuerzas de autodefensa nacional ya no son simples "samuráis de papel"», $A B C, 3$ de febrero de 1985 .

16 Manuel Fraga Iribarne, «Donde nace el sol», $A B C, 28$ de abril de 1981.

«La OPEP y los japoneses», La Vanguardia, 1 de noviembre de 1981.

Rosa Ovejero, «Japón, el modelo imposible para Europa», ABC, 24 de febrero de 1985.

19 Un enfoque típico en F. C., «Tajima: “La decisión se basa en el consenso”», La Vanguardia, 6 de diciembre de 1981; Manuel Blanco Tobío, «Genio para la adaptabilidad», $A B C, 28$ de febrero de 1985.

20 M. Lloberas Ribal, «La lucha de clases y el Japón», La Vanguardia, 10 de marzo de 1985.

21 Manuel Ibáñez Escofet, «La esperanza amarilla», La Vanguardia, 4 de diciembre de 1990. En un sentido muy similar, Fernando Jiménez-Ontiveros Solís, «Japón, ¿la nueva vía?», ABC, 29 de julio de 1982; Juan Insua, «La cultura de los ejecutivos», La Vanguardia, 23 de julio de 1985; Jordi Palarea, «El Japón como modelo», La Vanguardia, 14 de octubre de 1989.

22 Xavier Batalla, «En japonés», La Vanguardia, 12 de enero de 1990; Bosco Esteruelas, «Fujimori pide ayuda económica a Japón para la grave crisis de Perú», El País, 7 de marzo de 1990.

23 Carlos Sentís, «El Fuji andino», La Vanguardia, 17 de abril de 1990.

24 «Dos periodistas muertos por exceso de trabajo durante la enfermedad de Hirohito», La Nueva España, 11 de octubre de 1988; «El Gobierno japonés reconoce que se puede morir por exceso de trabajo», La Vanguardia, 15 de julio de 1992.

25 «Productivos, pero neuróticos», ABC, 23 de julio de 1981; Ero, «La calle y su mundo», La Vanguardia, 11 de abril de 1993.

26 Laureano Lázaro Araújo y Maria Amparo Gómez Álvarez, «La crisis de la Seguridad social y los fondos de pensiones / y 2», El País, 23 de abril de 1985. Una de las primeras menciones a la "japonización” como amenaza para la clase trabajadora corresponde, probablemente, a José Valentín Antón, secretario general de la UGT de Cataluña. «Jordi Pujol recibió a los miembros del secretariado de UGT», La Vanguardia, 17 de mayo de 1983. Para comprobar los usos del término en el terreno político pueden consultarse «Los gobiernos regionales y municipales rechazan el cierre de Santa Barbara», El País, 30 de marzo de 1994; Javier Casqueiro, «CC OO e IU lanzan sus primeros guantes al PSOE de Joaquín Leguina», El País, 20 de mayo de 1995.

27 Eugenio Madueño y Pedro Madueño, «El bocadillo y el japonés», La Vanguardia, 17 de mayo de 1993, sec. Revista.
} 
de algunos restaurantes colgasen carteles aclarando que no eran japoneses, sino chinos. ${ }^{28}$ Algún artículo incluyó la incompatibilidad cultural entre los motivos del abandono de la multinacional, y no faltaron textos que afeasen la falta de compromiso de Suzuki con Santana Motor, aunque el grueso de los artículos publicados tienden a justificar la posición de la empresa y a reprochar a los trabajadores y sindicatos que obstaculizasen cualquier solución. ${ }^{29}$ Incluso Moltó, secretario de Estado de Industria del último gabinete de Felipe González, llegó a sugerir que los trabajadores debían ser más conscientes de la situación mundial y entender que la producción no podía depender de sus necesidades. ${ }^{30}$

La trayectoria de las representaciones de Japón en el mundo fabril español, en todo caso, no puede disociarse de un proceso universal de violenta reorganización de las relaciones de producción que tuvo en la expansión del capital nipón a través de Occidente ${ }^{31}$ uno de sus rasgos más destacados. Esta expansión hizo proliferar multitud de obras que instaban a aplicar el modelo japonés de cooperación entre productores. La dirección de la planta británica de Nissan en Sunderland, por ejemplo, celebraba en sus anuncios que los trabajadores y la gerencia trabajasen unidos en lugar de competir entre ellos; una campaña televisiva incluso invitaba al espectador a imaginar un mundo sin conflictos ni huelgas (Holloway, 1998: 126-127). De hecho, Peter Wickens, uno de los managers de Nissan, reconocía que el principal objetivo de las nuevas técnicas de recursos humanos era conseguir una mano de obra que siguiera el patrón japonés (Wickens, 1988: 160). Según afirma Rodríguez Guzmán, el propio presidente de Santana Motor, Giménez Cassina, había amalgamado en su obra La gestión social del empresario (1985) "los principios del paternalismo autoritario en una versión adaptada de la gestión de la fuerza de trabajo de inspiración japonesa." (Rodríguez Guzmán, 2012: 263). Giménez Cassina sintetizaba en tres las razones de la superioridad competitiva de las empresas japonesas: la escasa regulación estatal, la sustitución de la lucha de clases por la "competición entre grupos y empresas", y la integración de la mayoría de los sindicatos en las direcciones de las empresas. (Rodríguez Guzmán, 2012: 264) Alston resumía gráficamente el atractivo de esta transformación: ningún sindicato japonés, según aseguraba, se atrevería a promover un conflicto que vulnerase el $w a^{32}$, esto es, que obstaculizase al colectivo en su "búsqueda de la armonía." (Alston, 1996: 59) En definitiva, aunque algunos autores discutieron que se pudiera diferenciar sin matices un Occidente "fordista" y una alternativa japonesa "posfordista" (Elger y Smith, 1991), y aseguraron que los trabajadores japoneses distaban de ser la mano de obra feliz y satisfecha que dibujaba la propaganda (Fucini, 1990; Woronoff, 1991: 37-38), la "japonización” se convirtió en un fetiche para buena parte de las elites occidentales.

\section{La imagen de Japón en la Asturias de la reconversión industrial}

La liberalización de la economía española erosionó desde los años cincuenta un modelo de desarrollo industrial que aspiraba a la soberanía energética y emplazaba en regiones periféricas, como es el caso de Asturias, explotaciones mineras e industrias siderometalúrgicas. La recesión provocada por la crisis energética, financiera e industrial de principios de los años setenta aceleró la reestructuración del mercado español y una desindustrialización cuyos costes humanos y económicos es difícil sobrevalorar (Köhler, 1996). Asturias es una de las regiones europeas que sufrieron de manera más dramática las consecuencias del agotamiento de un "ciclo histórico y un modelo de desarrollo correspondientes a la economía tradicional (carbón-acero, grandes empresas estatales, pequeñas explotaciones agrícolas)"; precisamente la entrada de España en la CE aceleró el declive de estas estructuras productivas e impuso "una lógica empresarial poco favorable en principio a territorios como el asturiano." (Tomé, 1999: 245-246). La intervención estatal amortiguó en cierta medida la quiebra de gran parte de las empresas hulleras y compensó parcialmente la irrupción en el mercado internacional de productos metalúrgicos a precios muy inferiores; sin embargo, la asunción de empresas con serios problemas financieros y productivos no hizo sino cronificar el declive de la comunidad, devenida prototipo de lo que la literatura especializada define como una 'vieja área industrial'." (García Blanco, 1998: 90). La reconversión asturiana se incardina en un proceso mundial de fragmentación y deslocalización del trabajo que encuentra su trasunto en la organización del tiempo dentro de las fábricas, tal y como estudiaron Castillo y López Calle en el caso de la planta de Volkswagen, en Navarra. La metodología del justo a tiempo, concluyen los autores, conllevaba un "diseño productivo donde la fragmentación del trabajo, primero en empresas, y luego, dentro de ellas,

28 Acerca del malestar de la plantilla véanse Carmen Del Arco, «"Tapeo” a la japonesa», El País, 4 de mayo de 1993; Carmen Del Arco, «Miyoshi, Ishii y Fernández», El País, 4 de mayo de 1993; José Bejarano, «El divorcio de Japón y Linares acaba en el juzgado», La Vanguardia, 23 de febrero de 1994, sec. Revista. La mención a los casos de xenofobia en Alfredo Semprún, «Linares: la hora de la desesperanza», $A B C, 27$ de febrero de 1994 ; «Coge el dinero y corre», El País, 25 de febrero de 1994.

29 Diferencias culturales en Bejarano, «El divorcio de Japón y Linares acaba en el juzgado»; «Las causas del abandono. Diez razones para desinvertir en España», La Vanguardia, 3 de octubre de 1994. Críticas a la política sindical del "todo o nada" en «Solución para Suzuki», La Vanguardia, 16 de marzo de 1994. En el mismo sentido, Antonio Papell, «Multinacionales en España», La Nueva España, 3 de diciembre de 1994; Joaquín Muns, «Seat, Suzuki y todo lo demás», La Vanguardia, 28 de marzo de 1994.

30 Juan Jesús Aznárez, «Moltó pide en Japón más inversión en alta tecnología en la automoción española», El País, 2 de julio de 1994.

31 Nos alejaría en exceso del objetivo de este artículo incluir algún comentario acerca del proceso de difusión del "modelo japonés" en Asia Oriental, cuya peculiar mezcla de ideología neoliberal con filosofías y religiones orientales se resumen en el concepto de "valores asiáticos". Véase Jayasuriya (1997) para una síntesis interpretativa y Avenell (2013) para un estudio de caso sobre la influencia del modelo japonés en Singapur.

32 La voz japonesa wa, generalmente traducida como "armonía", se refiere en este contexto a un sistema de relaciones sociales caracterizado por privilegiar el consenso del colectivo en detrimento de los deseos individuales. Para Ito Kimio, que sigue explícitamente a Hobsbawm y Ranger, el sentido contemporáneo del wa se establece en la época Meiji, constituyendo una tradición inventada con la que "las clases dominantes revisaron y reorganizaron parte de la historia antigua japonesa" para asentar su dominación sobre el conjunto de la nación. (Kimio, 1998: 37). Para estudiar la “invención de la tradición” japonesa tras la Restauración Meiji véanse Gluck (1987), Tanaka (1993) o Vlastos (1998). 
es una consecuencia necesaria.” (Castillo y López Calle, 2003: 104). La lógica de la competencia entre empresas se traduce, a menudo, en una competencia por imponer los salarios más bajos e intensificar el tiempo dedicado a la compañía, que reclama de sus trabajadores una disponibilidad mental y física cada vez más totalizante, percepción angustiosa que también relatan los trabajadores y trabajadoras de Suzuki en Gijón. En definitiva, el desempleo y la dislocación de la sociedad y economía de las comarcas más industrializadas de la comunidad preludiaron un largo período de intensos conflictos laborales, a menudo de índole defensiva, en los que el movimiento obrero asturiano luchaba, en el mejor de los casos, por ralentizar el avance de las deslocalizaciones y los ajustes de plantilla; en el peor, luchaba simplemente por sobrevivir.

Tal y como se pudo observar en los diarios de ámbito nacional, en la prensa asturiana convive la idea de la eficacia japonesa con el recelo hacia la "enfermiza" obsesión por el trabajo de los japoneses. Los casos -no demasiado infrecuentes- de muerte por agotamiento en Japón favorecieron que se prestase atención a las consecuencias más funestas de la explotación laboral japonesa resignificada, en todo Occidente, como "adicción al trabajo" ${ }^{33}$ Resulta de especial interés, en este sentido, el testimonio del por aquél entonces presidente de Ensidesa, Fernando Lozano, que manifestaba su disgusto ante la vida "dura y despiadada", de la "horrible" sociedad japonesa, en la que "el que no funciona queda fuera." ${ }^{34}$ Esta perspectiva, sin ser infrecuente, resultaba menos habitual que la que celebraba sin ulteriores reflexiones que las inversiones japonesas se instalasen en la comunidad. ${ }^{35}$ Resulta particularmente reveladora al respecto la insistencia con la que el Partido Popular del concejo minero de Mieres solicitaba, desde la oposición, que se hiciera un esfuerzo por atraer inversiones japonesas. ${ }^{36}$ El PP destacaba sistemáticamente que las empresas japonesas solo se instalarían allí donde hubiera "ventajas fiscales y paz social". ${ }^{37}$ El PP, de hecho, llegó a solicitar la intercesión del príncipe, aunque tras un año de insistencia, terminó por cejar en su insistencia. ${ }^{38}$

La visita del embajador Hiroshi Yokota a la Cámara de Comercio de Oviedo en 1980 permite explorar el interés por Japón y sus inversiones desde las primeras fases de la reconversión industrial. El artículo explica el "milagro japonés" a partir de la homogeneidad de criterio del pueblo japonés, su natural sentido cooperativo y al logro de establecer objetivos nacionales de largo alcance ya que, pese a ser Japón un conjunto de islas, "el sentimiento nacional es único entre todas ellas." ${ }^{39} \mathrm{Si}$ durante el primer franquismo la democracia era considerada un cuerpo extraño en Japón que lastraba sus virtudes tradicionales, en los primeros años de parlamentarismo liberal en España se tendía a elogiar la capacidad de Japón para conciliar la "adaptabilidad y eficacia del sistema democrático" con la voluntad de trabajo y el orden social. ${ }^{40}$ En cambio, se solía destacar que la baja productividad española y sus "altos niveles de incertidumbre en el comportamiento laboral" disuadían a los japoneses de implantar en el país proyectos industriales e inversiones sustanciales. ${ }^{41}$ La popularidad del modelo japonés tenía que ver, sin duda, con la percepción de que el país asiático había conseguido esquivar las convulsiones sociales características de los años ochenta y noventa en Asturias.

No cabe ignorar que sobre la economía asturiana pesa gravemente una leyenda de insurrección social que se inició a principio de siglo y que tiene como hitos o años de referencia el 17, el 34 y el 36; pero en los momentos actuales, aunque con lentitud, se va abriendo un clima de mayor y más pacífico entendimiento entre clases sociales. Las crisis hacen ver que los intereses de una y otra parte no están tan alejados como determinadas posiciones políticas propugnan; pero el camino a recorrer, si queremos llegar al que preside esas relaciones, no ya en el Japón, modelo que sería el óptimo en estos tiempos, sino al del resto de los países con los que tenemos intensas relaciones económicas y con los que pretendemos integrarnos, es largo. ${ }^{42}$

En el mismo sentido, Carlos Roces Felgueroso elogiaba que en Japón los sindicatos se dedicasen a "buscar fórmulas para atajar las causas de los males" en lugar de organizar huelgas y promover conflictos. ${ }^{43}$ En "Horas de trabajo", Pedro Pascual contrapone el rendimiento del trabajador japonés, que le dedica a la empresa más horas que ningún trabajador del mundo, con la incidencia de las huelgas en España, de lo que culpa a la influencia de Comisiones Obreras y del Partido Comunista. ${ }^{44}$ El contrato "de por vida" suscrito por los más de seis mil trabajadores de la Ford Motor estadounidense fue presentado como un triunfo del modelo japonés de seguridad laboral y compromiso con

33 Avello, por ejemplo, afirmó que los japoneses eran tan adictos al trabajo como "los cocainómanos a la cocaína.” Manuel Avello, «Japoneses», La Nueva España, 23 de marzo de 1990. En un tono más desenfadado, Javier Cuervo, «Laboradictos», La Nueva España, 1 de septiembre de 1990.

34 M. Rad, «Fernando Lozano, fiel a la isla durante treinta años», La Nueva España, 16 de agosto de 1985.

35 Luis F. Fidalgo, «El acuerdo de Derbi con Kawasaki completa la presencia de fabricantes japoneses de motocicletas en España», El País, 13 de enero de 1985; Javier Cuervo, «Tortilla y española», La Nueva España, 11 de agosto de 1990; D. E., «La inversión japonesa en España ha caído un 51 por 100 en los dos últimos años», $A B C, 23$ de febrero de 1994; Francesc Puigpelat, «Las empresas japonesas auxiliares del automóvil se instalan en España», El País, 17 de junio de 1991.

36 A. F., «Una delegación japonesa visita Langreo para estudiar los mercados comerciales», La Nueva España, 18 de julio de 1991 ; Pablo Toral, «La empresa japonesa Hokkaido Ibérica se instalará en Langreo», La Nueva España, 20 de julio de 1991. Luis Gancedo, «El PP pide a Japón que instale una fábrica de coches de Mazda en Mieres», La Nueva España, 18 de diciembre de 1991.

Luis Gancedo, «El PP pide a Japón que instale una fábrica de coches de Mazda en Mieres», La Nueva España, 18 de diciembre de 1991.

«El PP pide al Príncipe que medie en Japón por la comarca», La Nueva España, 26 de septiembre de 1992.

«El embajador Hiroshi Yokota, en la Cámara de Comercio», La Nueva España, 25 de marzo de 1980.

«La productividad japonesa», La Nueva España, 28 de octubre de 1980.

Ibid.

«Fernández-Pello: Rigor en el diagnóstico.», La Nueva España, 19 de abril de 1981.

Carlos Roces Felgueroso, «La captación de votos», La Nueva España, 31 de marzo de 1982.

Pedro Pascual, «Horas de trabajo», La Nueva España, 1 de noviembre de 1980. 
la empresa ${ }^{45}$ No mucho después, en una jornada empresarial celebrada en 1982 en La Granda, se estudió el caso de Japón, "invulnerable a las crisis económicas y al paro", para intentar desentrañar sus secretos y aplicarlos a Asturias. Entre las recetas halladas destacaba la convicción de que para establecer políticas de empleo y educación realmente efectivas se requería una "gran cohesión social y ausencia de conciencia de clase", así como que "las propias organizaciones sindicales colaboren en la aplicación de los avances tecnológicos" ${ }^{46}$ En definitiva, el prestigio del "milagro japonés" en Asturias, como sucedía en Occidente, integraba tanto la admiración por los éxitos económicos del país como la imaginación orientalizante de una cultura tradicional, ajena a muchos de los disturbios sociales y políticos propios de la modernidad. En este sentido, un repaso a algunos jalones de la cobertura periodística del asentamiento de la planta de Suzuki en Gijón y la huelga de 1990 permitirá profundizar en los usos sociales de la imagen de Japón, en general, y la percepción mediática de la conflictividad obrera, en particular.

\section{5. "Del peligro amarillo a la salvación oriental”. EI conflicto de Suzuki en Gijón.}

La empresa de motos asturiana Avello S.A. fue creada por el industrial vasco Alfredo Avello en los años cincuenta en el barrio obrero de Natahoyo; a mediados de los ochenta Suzuki se hizo con la mitad del capital de la empresa, en una época en la que las visitas de los inversores e industriales japoneses eran acontecimientos relevantes para el conjunto de la comunidad autónoma. ${ }^{47}$ En 1985 La Nueva España reseñó con detalle la visita de Ryuzo Nakamoto, ejecutivo representante de la multinacional Mitsubishi, en quien parecen encarnarse a la perfección los dos registros que conformaban la imagen de Japón a mediados de los ochenta: la tradicional espiritualidad nipona bajo la que se esconde el guerrero agresivo e implacable. En definitiva, el samurái de corbata, "reflejo de ese nuevo estilo japonés, a mitad de camino entre la placidez oriental y la agresividad comercial heredada de los guerreros samuráis." ${ }^{48}$ Esta percepción podría extenderse al conjunto de la sociedad. Javier Cuervo, por ejemplo, con motivo de la puesta en marcha de la acería LDIII en Avilés, repasa la vida social de los japoneses en la ciudad y destaca la fluidez con la que estos se habían integrado en la vida local. "A pesar de las expectativas", afirmaba el periodista, los japoneses no habían "sorprendido por sus costumbres laborales exóticas"; de hecho, según el testimonio de la propietaria de un mesón frecuentado por estos, que los considera "gente muy normal", con quienes había llegado a trabar amistad. ${ }^{49}$ En este clima favorable, Antonio Otero publica un artículo celebrando la llegada de Suzuki a Gijón en el que alaba la metodología japonesa, la "esperanza amarilla", de cuyos principios destaca su "flexibilidad dentro del rigor." 50 $\mathrm{Su}$ texto reflejaba el optimismo que la llegada japonesa había despertado en todos los responsables de la empresa, cuyos fundadores declaraban hallarse sorprendidos porque aquellos "pequeños hombrecillos sonrientes, de probada capacidad de trabajo y eficacia" terminasen instalándose en Asturias. ${ }^{51}$

A finales de 1989, cuando Suzuki ya era propietaria de todo el capital de la factoría gijonesa de Avello-Puch, el presidente de la FADE, Marcelino Somohano, expuso sus consideraciones acerca de los problemas económicos de Asturias. Las fallas del Principado las encuentra, principalmente, en problemas espirituales y culturales. La falta de entusiasmo y la moral baja estarían en la raíz de estos problemas, porque "los aspectos materiales son importantes, pero los no materiales o espirituales son absolutamente fundamentales para un país o una región como Asturias... Y es la Administración la que desincentiva esa esperanza en el futuro que podría tener el asturiano." ${ }^{52}$ La única salida que tendría Asturias sería apoyarse en su trabajo, "aunque parece que esta palabra no está de moda. Como ejemplo, ahí está Japón. El principal secreto para sacar a esta región de la crisis está en el trabajo de sus ciudadanos." ${ }^{\text {33 }}$ No es infrecuente que se recuerde en prensa que los inversores japoneses solicitaban entusiasmo por parte de la población de acogida. ${ }^{54}$ Esa apuesta global de la sociedad en beneficio de la empresa, que tan a menudo solicitan los articulistas de la prensa española, es precisamente lo que solicitará pocos meses después el embajador japonés Toru Ishii, exigiendo de las autoridades un trato similar al que Margaret Thatcher dispensaba al capital nipón en Gran Bretaña. ${ }^{55}$ El embajador, en una reunión entre empresarios y banqueros japoneses invitados por el Instituto de Fomento Regional, además de criticar la escasa infraestructura asturiana, insistió en que los problemas laborales que tenían lugar en Asturias a la hora de negociar con los sindicatos "no se plantean en las empresas de otros países". ${ }^{56}$ Saliendo al paso de los recelos de Ishii respecto del contexto social asturiano, la alcaldesa de Gijón Paz Fernández Felgueroso intentaba ofrecer una lectura optimista de la reunión, y se mostraba "moderadamente optimista sobre la posibilidad

\footnotetext{
«Casarse con la empresa», La Nueva España, 21 de mayo de 1982.

«Apretada jornada de trabajo en La granda», La Nueva España, 8 de noviembre de 1982.

Un estudio pormenorizado sobre la llegada del capital nipón a Avello-Puch y un balance crítico sobre la introducción de las nuevas metodologías laborales en Köhler (1996: 320-344). Interesa consultar también Avella Camarero y Fernández Barcala (1997).

Alberto Marcos, «La eficiente cordialidad de un ejecutivo enamorado de Asturias», La Nueva España, 24 de enero de 1985.

Javier Cuervo, «La nueva acería LDIII empezará a funcionar a finales de febrero», La Nueva España, 31 de enero de 1988.

Antonio Otero, «El capital nipón entra en Asturias sobre ruedas», La Nueva España, 4 de mayo de 1985.

Ibid.

Alberto Menéndez, «Lo que falla en Asturias es la falta de entusiasmo; incentivos, para poder salir de la crisis», La Nueva España, 2 de diciembre de 1989.

Ibid.

Pilar Rubiera, «Los inversores extranjeros piden un trato como el de Thatcher», La Nueva España, 19 de mayo de 1989.

Jose María Caso, «Suzuki condiciona su permanencia a contar con industrias auxiliares», La Nueva España, 25 de mayo de 1989.

«Una delegación de empresarios del Japón visitará Asturias antes del verano», La Nueva España, 19 de mayo de 1989.
} 
de conseguir inversiones japonesas." ${ }^{57}$ Faustino Álvarez, por su parte, uno de los pocos periodistas que cuestionaron de manera directa las exigencias de la patronal japonesa, respondió a Ishii enarbolando el orgullo laboral frente a "los planteamientos más brutales del capitalismo mundial”, relacionados con un sistema cultural que no podía comprender ni la estructura mental ni el "sentido de libertad" occidentales. ${ }^{58}$ En todo caso, el ya mencionado afán de atraer inversiones niponas a Asturias favoreció que las autoridades locales y autonómicas aceptasen las demandas del capital japonés y de la patronal, que exigían garantías de paz social. El presidente del Principado, Pedro de Silva, ante un colectivo de empresarios japoneses que planeaban visitar Asturias, loaba el apoyo que Suzuki recibía de parte de Gijón y del Gobierno como ejemplo del clima favorable a las inversiones del país oriental. ${ }^{59}$ La huelga en la planta de Gijón discurrió, en definitiva, en un clima mediático relativamente favorable a la dirección de la empresa, que recibe habitualmente el respaldo de las autoridades y los partidos mayoritarios, que hacían recaer en los sindicatos el peso de la responsabilidad de una eventual deslocalización.

En cuanto al clima social en el interior de la fábrica interesa consultar la obra de Amaya Caunedo que entrevistó a varios trabajadores y trabajadoras de Suzuki cuyos testimonios constatan las dudas o la hostilidad del personal ante los círculos de calidad, los ritmos de trabajo, o la organización del tiempo de ocio. Según afirma Caunedo, "todas las personas que han pasado por la cadena nos explican la alienación que se sufre en esos puestos de trabajo [los de una cadena de montaje moderna], la sensación de que es imposible trabajar a ese ritmo durante 8 horas seguidas, la angustia que te acompaña cuando sales del trabajo los primeros días...". (Caunedo, 2013: 5) De todas formas, la cobertura en prensa de la huelga de 1990 tiende a concentrarse casi exclusivamente en los conflictos entre los sindicatos y la dirección, así como en las grietas dentro del propio movimiento obrero. En el ámbito sindical se puede distinguir entre la postura intermedia de la Unión General de Trabajadores, de tradición socialdemócrata, que le causa alguna fricción con Comisiones Obreras, de tradición comunista, y más beligerante con la empresa. Ambos sindicatos mayoritarios, sin embargo, chocan con el sindicalismo alternativo de la Corriente Sindical de Izquierdas, emergente en esos años, que alertaba del peligro que suponía realizar cesiones frente a una empresa que, en última instancia, aspiraba a la deslocalización total de sus instalaciones gijonesas. La huelga comienza formalmente el 19 de marzo de 1990, con dificultades para establecer la interlocución entre el Comité de Empresa y la dirección de Suzuki, que ya el 4 de mayo anuncia en un comunicado enviado a prensa, bajo la simple rúbrica de "La Dirección", que no habría diálogo abierto mientras los trabajadores en huelga mantuvieran los piquetes y barricadas que impedían acceder al persona de la fábrica que "libremente quiere ejercer su derecho al trabajo." ${ }^{60} \mathrm{El}$ comunicado precipita los esfuerzos de UGT para mediar con la empresa, y ambas partes se disponen a elaborar un borrador de acuerdo, alcanzado finalmente el 16 de abril, que es criticado por el resto de centrales sindicales por "oxigenar a la empresa y romper la unidad del comité". ${ }^{61}$ Ese mismo día, algunos artículos en prensa destacaban que los japoneses se habían integrado satisfactoriamente en la comunidad y esgrimían fuentes anónimas que minimizaban los trastornos causados por la metodología japonesa en Suzuki. ${ }^{62}$

Al día siguiente de firmarse el preacuerdo entre la UGT y la dirección de la empresa, Javier Neira publica en $L a$ Nueva España una columna que, con motivo de la candidatura de Fujimori en Perú, elogiaba el modelo japonés. Neira da por extinta, de ahí la mención a Fukuyama en el título de la columna, toda ideología, y asegura que Fujimori anticipa un futuro político en el que pronto "un liberal será tan anacrónico como un marxista leninista." 63 Así, Japón y Fujimori representarían una suerte de salida tecnocrática más deseable que la propuesta por los "ideólogos salvadores de derecha e izquierda". Del peligro amarillo, concluye, "se está pasando a la salvación oriental, porque ningún país tiene el prestigio y el poder del Japón." ${ }^{64}$ El 15 de abril Ricardo Utrilla, igualmente inspirado en la candidatura de Fujimori en Perú, escribe en El Comercio una columna significativamente titulada "La solución japonesa" ${ }^{65}$ La columna de Utrilla, como la de Neira, encuentra en Japón y en Fujimori el símbolo de una solución tecnocrática que trascendería las recetas fallidas de viejas ideologías ancladas en modelos sin respuesta, de modo que "votar japonés", sugiere el autor, podría ser el mejor lema electoral en varios países. Japón comienza a exportar, en definitiva, "políticos de primera". ${ }^{66}$ También el 15 de abril ve la luz, en este caso en La Voz de Asturias, un texto de Luis Vega Escandón, emblema de la democracia cristiana en Asturias, que aseguraba, también con ecos de Fukuyama en su argumentación, que la defunción de los conflictos de clase resultaba inminente. Se abría, forzosamente, una época que requería profundizar en la economía social de mercado a partir de una nueva concepción de la empresa, en la que obreros y patronos cooperasen para alcanzar el máximo beneficio mutuo. ${ }^{67}$ Los tres artículos, por tanto, describen la vía japonesa como un camino hacia la economía de mercado que permitiría superar de forma armónica las trabas ideológicas que impedían el aumento de la productividad.

\footnotetext{
Jesús Cuartas, «Duras críticas del embajador japonés a la conflictividad laboral asturiana», La Nueva España, 20 de mayo de 1989.

Faustino Álvarez, «La bronca del japonés», La Nueva España, 21 de mayo de 1989.

«Una delegación de empresarios del Japón visitará Asturias antes del verano».

«Comunicado de Suzuki Motor España, S.A.», El Comercio, 4 de abril de 1990.

«UGT propone negociar sobre el conflicto de Suzuki», El Comercio, 6 de abril de 1990; S. E., «Suzuki podría poner fin hoy a la huelga tras el principio de acuerdo con UGT», La Voz de Asturias, 16 de abril de 1990.

Eduardo García, «Suzuki, parada desde hace tres semanas por una diferencia de ocho millones anuales», La Nueva España, 11 de abril de 1990.

Javier Neira, «Fukuyama, Fujimori y Fumanchu», La Nueva España, 12 de abril de 1990.

Ibid.

Ricardo Utrilla, «La solución japonesa», El Comercio, 15 de abril de 1990

Ibid.

Luis Vega Escandón, «La huelga», La Voz de Asturias, 15 de abril de 1990.
} 
Mientras, el conflicto en Suzuki iniciaba su fase final con una nueva oferta de convenio colectivo planteado por la compañía que incluía una importante subida salarial. ${ }^{68} \mathrm{~A}$ partir del día 16 aumenta la presión sobre el Comité de empresa, instado a aceptar el preacuerdo alcanzado por Suzuki y UGT. ${ }^{69}$ Por el otro, se mantenían las amenazas de deslocalización: Suzuki se declaraba dispuesta a trasladar su factoría a Cataluña si no encontraba en Asturias un clima adecuado para su desarrollo industrial. También se insistía en que el preacuerdo con UGT podría conjurar el peligro de cierre y evitar que en Asturias se repitiera la derrota sufrida por la plantilla de la fábrica de Monroe. ${ }^{70}$ De tal forma, se hacía reposar sobre los trabajadores la responsabilidad de una eventual deslocalización, que parecía cada vez más cercana tras fracasar una asamblea abandonada por UGT al no tomarse en consideración su preacuerdo de convenio. ${ }^{71}$ Los choques entre las diversas sensibilidades políticas y sindicales se recrudecen y los medios recogen, en fin, con detalle las discrepancias entre las centrales sindicales, proyectando una visión del conflicto relativamente sesgada en la que gran parte de su desarrollo consistía en enfrentamientos entre los propios trabajadores. A pesar de la mediación del Delegado de Trabajo y un preacuerdo de última hora alcanzado entre UGT, Comisiones Obreras y Suzuki, las asambleas de trabajadores votan mantener la huelga por un escaso margen. La dirección de Suzuki incrementa entonces sus amenazas, ${ }^{72}$ hasta que logra fracturar la asamblea y un grupo de 35 trabajadores solicita que se desconvoque la huelga para regresar a sus puestos de trabajo. ${ }^{73} \mathrm{~A}$ partir del 21 la prensa comienza a explorar otros aspectos del conflicto. En "Los japoneses no lo entienden", La Voz de Asturias intentaba profundizar en la visión y razones de Suzuki. La directiva, afirmaba el texto, parecía no entender que los sindicatos hubieran sido desbordados por los trabajadores, y recelaba del silencio de las autoridades municipales y autonómicas. El artículo reconstruye la historia de la empresa desde la perspectiva japonesa, destacando las graves dificultades que sufría la planta de Gijón, salvada "travesía por el desierto" por el capital nipón: "Dos culturas están enfrentadas (...) la japonesa, con la eficacia como norte, y la latina, que parece no ser muy bien entendida en el Imperio del sol naciente." ${ }^{74}$ La segunda parte del artículo responsabiliza parcialmente a la Corriente Sindical de Izquierdas por haberse opuesto al principio de acuerdo alcanzado en la Delegación de Trabajo. El conflicto concluye con el regreso de la mitad de la plantilla al trabajo, y el Comité de Empresa, "desahuciado" ${ }^{75}$ Tras la firma del convenio colectivo, ${ }^{76}$ lo único que restaba era realizar un balance de daños, en el la empresa impuso su visión del conflicto. ${ }^{77}$ El presidente asturiano Pedro de Silva achacó a la "insuficiente maduración sindical" una huelga que consideraba difícil de comprender, cuyas repercusiones preveía "muy duras." ${ }^{78}$ Toru Ishii, el embajador japonés que inició el cruce de declaraciones al solicitar un trato similar al de Margaret Thatcher, aseguró que la huelga había sido una experiencia positiva para la dirección de Suzuki, aunque advertía que si las noticias del conflicto llegaban a Japón, otras empresas, como Kawasaki, podrían repensarse sus inversiones en Asturias. ${ }^{79}$ "Así", concluye un periodista, "a los ojos de los japoneses, Asturias vuelve a aparecer como una región conflictiva", poniéndose, por tanto, en riesgo todas las inversiones, las efectivas y las que podrían haber llegado a la comunidad. ${ }^{80}$

\section{Conclusiones}

En este artículo no se ha pretendido discutir el funcionamiento de las metodologías laborales de inspiración japonesa, ni reducirlas a un mero dispositivo de control; tampoco se cuestionan las interacciones entre la dimensión simbólica y material de la vida social; más bien al contrario, se ha intentado llamar la atención sobre el contexto sociopolítico que enmarca tanto el éxito del "modelo japonés" como su difusión e implantación, y las relaciones de este con las imágenes más comunes del discurso orientalista. La circulación de estas imágenes solo puede comprenderse plenamente desde una perspectiva global que tenga en cuenta, de forma simultánea, el contexto sociopolítico que define al sistema productivo japonés y las funciones sociales que cumple, tanto en Japón como en los países en los que se aplica, de tal suerte que los discursos que celebran el modelo japonés deben analizarse, sin perjuicio de otros enfoques interesados en sus aspectos procedimentales, como un espacio de interacción compleja entre diversos procesos históricos, relaciones de poder y construcciones culturales. La representación contemporánea de Japón se consagró, como ya se ha comentado en el artículo, tras la Segunda Guerra Mundial, cuando Estados Unidos comenzó a rehabi-

\footnotetext{
«Suzuki ofrece un convenio colectivo por tres años con una subida salarial del 9,5 por ciento para 1990», El Comercio, 15 de abril de 1990 .

79 Francisco De la Ballina, «Toru Ishii cree que la huelga fue «una experiencia positiva» para la dirección de Suzuki», La Nueva España, 27 de abril de 1990.

80 J. G., «Kawasaki sopesa sus planes para venir a Asturias después del conflicto de la Suzuki», La Voz de Asturias, 28 de abril de 1990.
} 
litar la imagen pública de su antaño odiado enemigo para convertirlo en la pieza clave de su estrategia para contener el avance del comunismo en el Pacífico. Las teorías de Ruth Benedict y otros autores contratados por las autoridades de la ocupación dibujaron una cultura tradicional desestabilizada por el violento encuentro con la modernidad -considerada atributo exclusivo de Occidente-, en la que primaban la vergüenza frente a la culpa, lo colectivo frente a lo individual y la jerarquía frente a la libertad. Esta duradera representación contrasta con la inmensa movilización obrera y estudiantil de la posguerra, cuya trayectoria no puede abstraerse de la intervención estadounidense en la política japonesa. Es sabido que la administración de MacArthur, tras establecer un entramado institucional progresista en los primeros años de la ocupación, reorientó sus políticas hacia una represión del movimiento obrero que discurrió paralela a la rehabilitación de miles de políticos y cuadros que habían desempeñado roles relevantes durante el período fascistizante del imperialismo japonés. Según Tadashi Hanami, los trabajadores quedaron tras ello "firmemente sometidos al control de los administradores de la empresa", de manera que los sindicatos "apenas podían resistir o regular el efecto de la introducción de una nueva tecnología por parte de los administradores, o las expectativas de producción." (Hanami, 1983: 161). El "milagro económico" japonés y su estructura sociolaboral es inseparable de este contexto de luchas políticas y sociales, obliteradas por un discurso que convierte relaciones de poder en inclinaciones culturales. ${ }^{81}$ Como ya se comentó en la introducción, los autores de la corriente denominada nihonjinron amalgamaron tradiciones del pensamiento japonés con las representaciones orientalistas más conocidas en Occidente para dar lugar a un cuerpo de discursos que han sido descritos como una suerte de "nacionalismo cultural" replicado por la propaganda de las grandes empresas, que invitaba a sus obreros a cooperar con los propietarios (Yoshino, 1992). También el gobierno, evidentemente, promocionó estas imágenes; Horio ha investigado el manual Kitai sareru ningen [La imagen que se espera de los japoneses] que pretendía modular a los individuos de manera que asumieran, en la educación secundaria, como propios los valores tradicionales de obediencia a las jerarquías y, claro está, a las autoridades (Horio, 1988: 159). Desde esta perspectiva sociocultural, recorrida por el presente artículo, cabe afirmar que las representaciones orientalistas de Japón, forjadas en su aspecto definitivo por una confluencia de intereses geopolíticos y de clase, proporcionaron argumentos para reificar las nuevas relaciones de producción insertas en el marco de la globalización neoliberal como un destilado deseable de las recetas culturales que sustentaban el "milagro japonés". Las virtudes atribuidas a las nuevas técnicas sociolaborales se unieron a los viejos argumentos contra el sindicalismo de clase dando lugar a un discurso que denunciaba las resistencias contra las nuevas dinámicas productivas como una muestra de egoísmo individualista que debía dejar paso a la generosidad y compromiso con la empresa propios de la cultura nipona. Esta dinámica no resulta extraña al funcionamiento general del discurso orientalista. Los discursos que deploraban el auge del feminismo en Occidente por fomentar la pérdida de las virtudes femeninas que mantenían la cohesión de las familias y la sociedad, esgrimieron como un contramodelo más deseable a la mujer japonesa, representada como un ser sumiso, dulce y pasivo — construcción cultural que tiene su símbolo más conspicuo en la reinvención decimonónica de la geisha - dispuesta siempre a satisfacer al varón blanco. Del mismo modo, las representaciones del acomodaticio obrero japonés se opusieron a la intransigencia del obrero occidental, de tal suerte que las relaciones laborales perdían su naturaleza sociopolítica para convertirse en un problema cultural, incluso psicológico. Así, el objetivo declarado de las elites industriales ya no sería vencer en la lucha de clases, sino trascenderla; no habría que confrontar con el movimiento obrero, sino adaptarlo a una cultura consensual, milenaria y triunfante. Este discurso, claro está, no es más que una faceta del complejo crisol de prácticas sociales y discursivas que se entrecruzan en la reorganización de las relaciones laborales durante el período considerado en este artículo, y conviene tener en cuenta, como apunta Holloway, que el capital japonés no hizo sino proporcionar un conjunto de técnicas y esquemas novedosos, pero que fueron "las derrotas de los obreros en Cowley, Longbridge y en otras partes" las que hicieron posible que la dirección los utilizara a manera de dispositivos de control (Holloway, 1998: 137-138). En definitiva, el material revisado en este artículo para los casos español y asturiano permite inferir que las clases hegemónicas encontraron en el imaginario orientalista un poderoso aliado con el que afianzar sus posiciones y diseñar, por utilizar la expresión que da título a la obra de José Sierra (1998), al obrero soñado.

\section{Obras citadas}

Abegglen, J.C. (1958). The Japanese Factory. Aspects of its Social Organization, Free Press, Nueva York.

Ahmad, A. (1994). In Theory: Classes, Nations, Literatures, Verso, Londres.

Beeby, A. y Rodríguez, M.T. (2009). “Millán-Astray’s Translation of Nitobe’s Bushido: The Soul of Japan”, META, 54, $218-232$. Alston, J.P. (1996). The American Samurai, Walter de Gruyter, Berlin.

Avella Camarero, L. and Fernández Barcala, M. (1997), "Implantación de los sistemas de producción just in time en Occidente: la experiencia de Suzuki Motor España", Revista Asturiana de Economía, 19, 197-220.

Avenell, S. (2013). "Beyond mimesis: Japan and the uses of political ideology in Singapore", in Paul Morris, N.S. (Ed.), Imagining Japan in Post-War East Asia: Identity Politics, Schooling and Popular Culture, Routledge, Nueva York, 22-49.

Barlés, E. (2003), "Luces y sombras en la historiografía del Arte japonés en España”, Artigrama, 18, $23-82$.

81 Se ha vinculado el ascenso de la nihonjinron con la derrota política de la izquierda japonesa y el consiguiente retroceso de los discursos progresistas (Sugimoto, 2010: 261; Masanao, 1978: 35). 
Beechler, S., Ito, K. and Pucik, V. (1986). “American organizational theory in Japan: Western concepts, Japanese spirit”, Sociology and Social Research, 71, 20-26.

Benedict, R. (2006). El Crisantemo y la espada, Alianza Editorial, Madrid.

Bhabha, H. (2002). "La otra pregunta", El Lugar de la cultura, Manantial, Buenos Aires, 91-110.

Bonazzi, G. (1993). "Modelo japonés, toyotismo, producción ligera: algunas cuestiones abiertas", Sociología Del Trabajo, 18, 3-22.

Bouchard, J. (2017). Ideology, Agency, and Intercultural Communicative Competence. A Stratified Look into EFL Education in Japan, Hokkai Gakuen University, Sapporo.

Caunedo, A. (2013).Deslocalizad@s, AFOHSA, Oviedo.

Cole, R.E. (1971). Japanese Blue Collar. The Changing Tradition, University Of California Press, Berkeley.

Cuesta Ávila, R. (2003). Japón En Jaén: Intersección de identidades en un centro de producción fabril, Sanmartín Arce R. y Moreno Navarro, I. (dirs.), Universidad Complutense de Madrid, Madrid.

Dale, P. (1990). The Myth of Japanese Uniqueness, St. Martin's Press, Londres.

Dore, R.P. (1987). Taking Japan Seriously: A Confucian Perspective on Leading Economic Issues, Stanford University Press.

Dore, R.P. (2005). Capitalismo bursátil: Capitalismo de bienestar, Ediciones Akal, Madrid.

Dower, J. (1999). Embracing Defeat: Japan in the Wake of World War II, W.W. Norton \& Company/New Press, Nueva York.

Dreyfus, G. (2005). "Are we prisoners of Shangrila? Orientalism, nationalism and the study of Tibet", Journal of the International Association of Tibetan Studies, 1, 1-21.

Elger, T. and Smith, C. (1991). Global Japanization?: The Transnational Transformation of the Labour Process, Routledge, Nueva York.

Fallows, J. (1991). More Like Us: Making America Great Again, McMillam Academic and Professional Ltd, Nueva York.

Fucini, J.J. (1990). Working for the Japanese, Simon and Schuster, Nueva York.

García Blanco, J.M. (1998). "Declive económico y políticas regionales: el caso de Asturias”, REIS: Revista Española de Investigaciones Sociológicas, 83, 87-199.

Gluck, C. (1987). Japan's Modern Myths, Princeton University Press, Nueva Jersey.

Gorer, G. (1941). Japanese Character Structure and Propaganda, Yale University Press, New Haven.

Guarné, B. (2011). “Shall we westernize? Sobre la idea de 'Occidente’ en el imaginario japonés contemporáneo”, en Barlés, E. and Almazán Tomás, V.D. (coords.), Japón y El Mundo Actual, Prensas Universitarias de Zaragoza, Zaragoza, 721-744.

Gustafsson, J. (2004). "El cronotopo cultural, el estereotipo y la frontera del tiempo: la preterización como estrategia de representación del 'Otro'", Revista de Estudios Culturales de La Universitat Jaume I, 1, 137-147.

Hampden-Turner, C. and Trompenaars, A. (1993). The Seven Cultures of Capitalism: Value Systems for Creating Wealth in the United States, Japan, Germany, France, Britain, Sweden, and the Netherlands, Currency Doubleday, Nueva York.

Hanami, T. (1983). "The function of the law in Japanese industrial relations", en Shirai, T. (coord.), Contemporary Industrial Relations in Japan, University of Wisconsin Press, Wisconsin, 161-177.

Hofstede, G. and Bond, M.H. (1988). "The Confucius connection: from cultural roots to economic growth", Organizational Dynamics, 16, 5-21.

Holloway, J. (1998). "La rosa roja de Nissan”, Cuadernos Del Sur, 7, 113-144.

Horio, T. (1988). Educational Thought and Ideology in Modern Japan, University of Tokyo Press, Tokio.

Hugh Fritzpatrick, E.H. (1909), The Coming Conflict of Nations, or the Japanese American-War; a Narrative, H. W. Bokkeb, Illinois.

Jayasuriya, K. (1997), “Asian values as reactionary modernization”, Nordic Newsletter of Asian Studies, 19-27.

Karatani, K. (2000). "Uses of aesthetics: after orientalism”, Edward Said and the Work of the Critic: Speaking Truth to Power, Duke University Press, Durham, 139-152.

Kimio, I. (1998). "The invention of wa and the transformation of the image of Prince Shōtoku in modern Japan", en Vlastos, S. (coord.), Mirror of Modernity. Invented Traditions of Modern Japan, University of California Press, Berkeley, pp. 37-48.

Köhler, H.-D. (coord.). (1996). Asturias: El declive de una región industrial, Trea, Gijón.

Köhler, H.-D. (2001). "La 'máquina que cambió el mundo' cumplió diez años. El debate sobre la 'producción ligera'”, Sociología Del Trabajo, 41, 75-100.

López Calle, P. y Castillo, J.J. (2003). Los obreros del Polo. Una cadena de montaje en el territorio, Editorial Complutense, Madrid.

Manabe, K. y Befu, H. (1992). "Japanese cultural identity. An empirical investigation of nihonjinron”, Yearbook of the German Institute of Japanese Studies, 4, 89-102.

Marsh, R.M. y Mannari, H. (2015), Modernization and the Japanese Factory, Princeton University Press, Princeton.

Masanao, K. (1978). "Nihon bunkaron no rekishi”, Shigaku Zasshi, 87, 3, 1-35.

Mears, H. (1948), Mirror for Americans: Japan, Houghton Mifflin, Boston.

Minear, R.H. (1980). “Orientalism and the study of Japan”, Journal Of Asian Studies, 39, 507-517.

Oinas-Kukkonen, H. (2003), Tolerance, Suspicion, and Hostility: Changing U.S. Attitudes toward the Japanese Communist Movement, 1944-1947, Greenwood Press, Westport.

Robertson, J. (1998). "When and where Japan enters: American anthropology since 1945”, en Hardacre, H. (coord.), The Postwar Developments of Japanese Studies in the United States, Brill, Leiden, 294-335. 
Rodao, F. y Almazán Tomás, D. (2006). “Japonizar España: la imagen española de la modernización del Japón Meiji”, en Gómez-Ferrer Morant, G. (coord.), Modernizar España 1898-1914. Congreso Internacional: Comunicaciones, Universidad Complutense de Madrid, Madrid.

Rodríguez Guzmán, C. (2012). La gestión de la fuerza de trabajo en Santana Motor: De metalúrgicas Santa Ana al Parque de Proveedores, Diputación Provincial de Jaén, Jaén.

Said, E. (2002). Orientalismo, Mondadori, Madrid.

Sierra Álvarez, J. (1998), El obrero soñado. Ensayo sobre el paternalismo industrial (Asturias, 1860-1917), Siglo XXI, Madrid. Shibusawa, N. (2006). America's Geisha Ally. Reimagining the Japanese Enemy, Harvard University Press, Harvard.

Sugimoto, Y. y Mouer, R. (1986). Images of Japanese Society, Kegan Paul, Londres.

Sugiyama Lebra, T. (2004). The Japanese Self in Cultural Logic, University of Hawaii Press, Honolulu.

Taira, K. (1970). Economic Development and the Labor Market in Japan, Columbia University Press, Nueva York.

Takemae, E. (2002). The Allied Occupation of Japan and its Legacy, Continuum, Nueva York.

Thurow, L.C. (1992). Head to Head: The Coming Economic Battle among Japan, Europe, and America, William Morrow \& Company, Nueva York.

Tomé Fernández, S. (1999). “La nueva geografía económica de Asturias”, Ería, 50, 245-263.

Tsurumi, K. (2015). Social Change and the Individual, Princeton University Press, Princeton.

Vlastos, S. (1998). Mirror of Modernity. Invented Traditions of Modern Japan, University of California Press, Berkeley.

Vogel, E.F. (1979). Japan as Number One: Lessons for America, Harvard University Press, Cambridge.

Wells, H.G. (2000). Una utopía moderna, Océano de México, México, D.F.

White, H. (1992). Identity and Control: A Structural Theory of Social Action, Princeton University Press, Nueva Jersey.

Wickens, P. (1988). The Road To Nissan: Flexibility, Quality, Teamwork, McMillan, Basingstoke.

Yoshino, K. (1992). Cultural Nationalism in Contemporary Japan: A Sociological Enquiry, Routledge, Nueva York. 